\title{
Non-tuberculous mycobacterial lung disease: a brief review focusing on radiological findings
}

\author{
Laura Raniere Borges dos Anjos ${ }^{[1]}$, Poliana Lopes Parreira ${ }^{[2]}$, Pedro Paulo Teixeira Silva Torres ${ }^{[2],}$ \\ André Kipnis ${ }^{[1]}$, Ana Paula Junqueira-Kipnis ${ }^{[1]}$ and Marcelo Fouad Rabahi ${ }^{[2]}$
}

[1]. Universidade Federal de Goiás, Instituto de Patologia Tropical e Saúde Pública, Departamento de Biociências e Tecnologia, Goiânia, GO, Brasil. [2]. Universidade Federal de Goiás, Faculdade de Medicina, Departamento de Clínica Médica, Goiânia, GO, Brasil.

\begin{abstract}
The incidence and prevalence of lung disease caused by non-tuberculous mycobacteria (NTM-LD) has increased worldwide and its diagnosis represents a complex challenge. This article aims to review the tomographic findings of NTM-LD in order to facilitate their definitive diagnosis. The search for publications on the subject was performed in PMC and Scielo using the keywords 'non-tuberculous mycobacteria', 'lung disease and computed tomography (CT)' and 'radiological findings'. The radiological findings described by 18 articles on mycobacteriosis were reviewed. In addition, CT images of patients diagnosed with NTM-LD were considered to represent radiological findings. Eighteen publications were used whose main findings were pulmonary cavitation (88.9\%), bronchiectasis (77.8\%), and pulmonary nodules $(55.6 \%)$. Despite the overlaps in imaging-related analysis of myocobacterioses with other pulmonary infections, such as tuberculosis, the predominant involvement of the middle lobe and lingula should raise suspicion for NTM-LD.
\end{abstract}

Keywords: Non-tuberculous mycobacteria. Lung disease. Computed tomography. Radiological findings.

\section{INTRODUCTION}

Mycobacteria are a unique genus, called Mycobacterium, which are members of the family Mycobacteriaceae and the order Actinomycetales ${ }^{1,2}$. It is speculated that mycobacteria emerged 150 million years ago and so far over 170 different species and subspecies have been identified. These species can be organized into three groups: Mycobacterium tuberculosis complex (MTBC), M. leprae, and non-tuberculous mycobacteria (NTMs) ${ }^{3}$.

NTMs, previously identified as atypical mycobacteria, are defined as a heterogeneous group of species with distinct genotypic and phenotypic characteristics than MTBC or M. leprae ${ }^{4,5}$. NTMs are geographically distributed heterogeneously and can be found in animal species, vegetation, biofilms and especially in water and soil ${ }^{4,6-7}$.

The human pathogenicity of NTMs has been of interest to the scientific community, but this has not been the case always ${ }^{8}$. The

\footnotetext{
Corresponding author: Dr. Marcelo Fouad Rabahi.

e-mails: mfrabahi@gmail.com

(D) https://orcid.org/0000-0002-4050-5906

Received 7 May 2020

Accepted 29 June 2020
}

first description of pathogenic NTMs occurred in 1950 when around $2 \%$ of patients initially diagnosed with tuberculosis (TB) did not respond to traditional treatments and were subsequently diagnosed with mycobacterial infections that did not cause tuberculosis ${ }^{8,9}$. Since then, other studies are being conducted to improve the understanding of the pathophysiological mechanisms involved in NTM-related diseases ${ }^{10}$.

Non-tuberculous lung disease (NTM-LD) is the most common infection caused by NTMs, especially in immunosuppressed individuals. NTM-LD is not reportable to public health authorities and therefore it is difficult to estimate its epidemiological characteristics. Nevertheless, it is noted that the incidence and prevalence of NTM-LD has been increasing considerably in several regions of Brazil ${ }^{4}$. It is also suspected that other regions are experiencing a silent epidemic of this disease $e^{4,11}$.

Additionally, the diagnosis of NTM-LD requires compatible clinical and radiological findings, along with two or more positive sputum samples for the same NTM species or one positive bronchial wash/lavage or compatible histopathological findings with at least one positive culture ${ }^{12}$. Fungal infections or other mycobacterial infections might present similar clinical manifestations and radiological findings and so they pose an additional challenge for the 
correct microbiological identification and diagnosis ${ }^{12,13,14}$. Hence, NTM-LD represents a complex challenge for patients, health care, and health authorities around the world ${ }^{12}$.

This article reviewed the radiological findings described in other articles on MNT-LD to identify the major pulmonary changes presented by these patients. The results obtained could contribute in differentiating between MNT-LD and TB and can facilitate the diagnosis of MNT-LD.

\section{METHODOLOGY}

For this review, the search and selection of publications was performed on the following platforms: Pubmed Central (PMC) and Scientific Eletronic Library Online (SciELO). The search terms used were 'non-tuberculous mycobacteria', 'lung disease and computed tomography', and 'radiological findings'.

The inclusion criteria for articles were those published in Portuguese, English or Spanish from 1999 to 2019. The reference lists of all retrieved articles were checked to identify other eligible publications. Comments, gray literature and other publications that did not meet the inclusion criteria were excluded.

The flow diagram of this review is detailed in Figure 1. In total, 18 articles were considered and all the radiological findings are summarized in Table 1. To represent tomographic findings, computed tomography (CT) images (Figure 2 and Figure 3) obtained from archives of medical assistants in the region of Goiânia, Goiás, Brazil, were used. It is important to highlight that these images were set as anonymous by the professionals in charge before being made available for this review.

\section{EPIDEMIOLOGY}

Considering the epidemiological data of NTM-LD available in the literature, it is observed that the disease prevalence varies between regions. In general, the epidemiology of this disease accompanies the distribution characteristic of NTM species ${ }^{4}$.

Based on the surveyed literature, the most frequent species are $M$. kansasii and the M. avium complex (MAC), which includes the subspecies $M$. avium, M. intracellulare, and $M$. chimaera. These pathogens are very common in Europe ( $80 \%$ of cases), North America, South Korea and are often associated with LD cases that are similar to $\mathrm{TB}^{6,15-17}$.

M. xenopi is also associated with LD and is found in Europe and in certain regions of Canada. In the Middle East, the most common clinical isolate is $M$. simiae, which can cause infection in various organs, especially the lung ${ }^{6,15,18}$.

Recently, other NTMs have emerged as human pathogens, including M. fortuitum, M. chelonae and the M. abscessus complex (MABSC $^{6,19}$. Genome sequencing technology has enabled the taxonomic organization of the MABSC into three subspecies: M. abscessus subsp. bolletii, M. abscessus subsp. abscessus and M. abscessus subsp. massiliense, and these are common in Asia, Oceania and South Korea ${ }^{11,15,20,21}$. These emerging NTMs can cause skin, soft tissue, and central nervous system infections and can also lead to $\mathrm{LD}^{19,20,22,23}$. LD caused by MABSC mainly affects patients with predisposed diseases such as cystic fibrosis ${ }^{20,24}$.

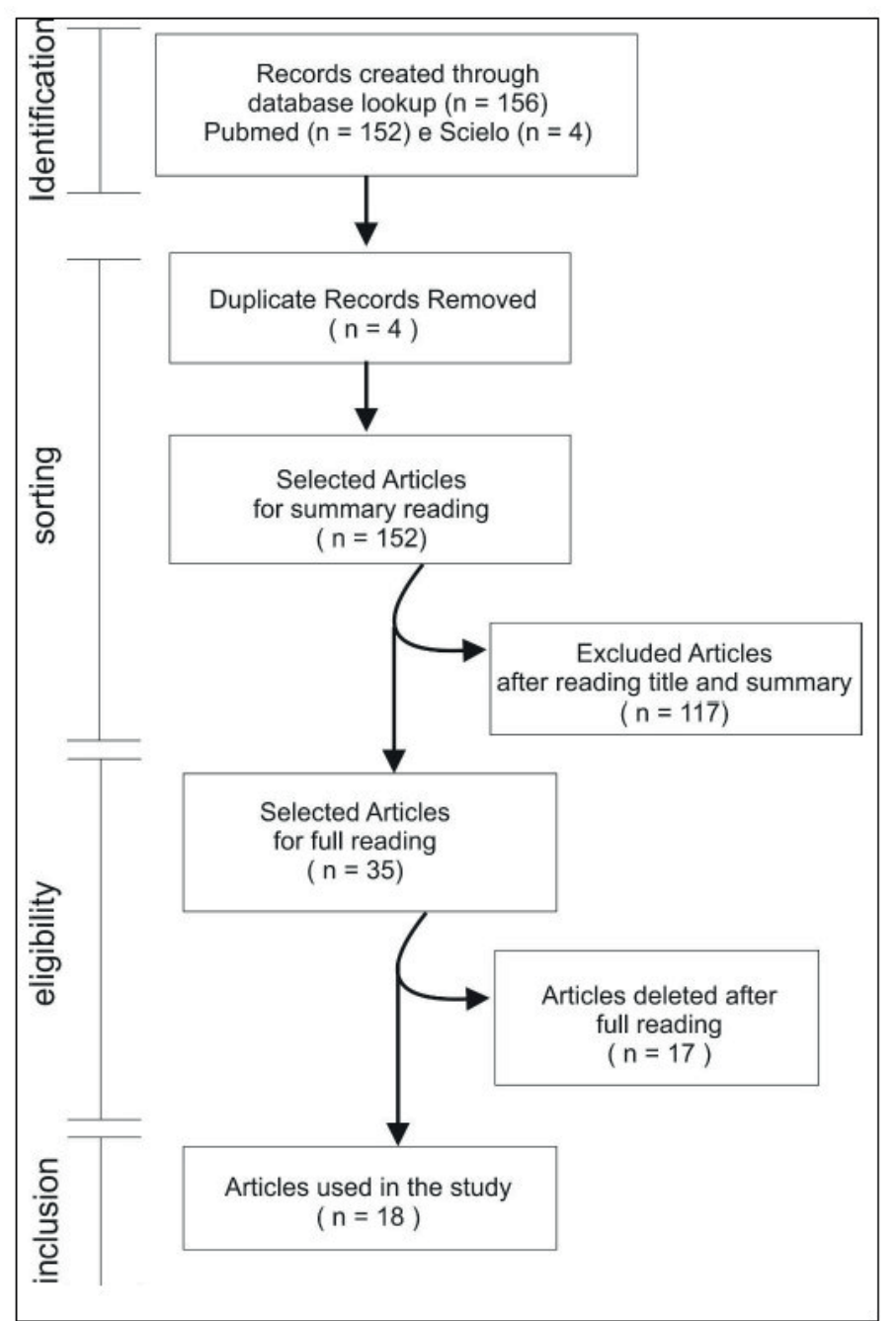

FIGURE 1: A flow diagram describing the stages of article identification, screening, eligibility and inclusion which are considered in this brief review.

\section{TRANSMISSION AND CLINICAL MANIFESTATIONS}

NTM-LD guidelines include the various forms of transmission of the etiological agent. For a long period of time, it was accepted that the transmission of NTMs occurred through the environment. It was later reported that some species were related to medical devices used in surgical procedures or esthetic treatments ${ }^{25}$. Recently, direct transmission of NTM species among cystic fibrosis patients has also been documented ${ }^{20}$.

Once transmitted, NTMs can settle in any organ and can develop an asymptomatic infection or can lead to a disseminated disease that can be fatal to humans ${ }^{25,26}$. The lung is the target organ of NTM$\mathrm{LD}$ and its involvement implies different clinical manifestations that negatively impact patients' quality of life ${ }^{27}$. It is described in the literature that NTM-LD might occur in three prototypic forms: fibrocavitary disease, nodular bronchiectasia, and hypersensitivity pneumonitis ${ }^{28}$, and the radiological findings of these three forms were described in various articles as cited in Table $\mathbf{1}$.

Signs and symptoms of fibrocavitary disease have traditionally included nonspecific symptoms such as purulent sputum, 
TABLE 1: Radiological findings of CT scans from patients with NTM-DP.

\begin{tabular}{|c|c|c|c|c|}
\hline Author (Year of publication) & Region/Country & $\begin{array}{l}\text { Number of patients } \\
\text { with NTM infection }\end{array}$ & Methodology ${ }^{2}$ & Radiological findings $^{3}$ \\
\hline Fujita et al. (1999) ${ }^{36}$ & Kagawa, Japan & 5 & CT & $\begin{array}{l}\text { bronchiectasis; cavitation; centrilobular nodules; } \\
\text { consolidation; bronchiolitis; }\end{array}$ \\
\hline Koh et al. $(2002)^{46}$ & Seoul, Korea & $(-)$ & CT & $\begin{array}{l}\text { MAC: upper lobe cavitation; nodules; } \\
\text { bronchiectasis; progressive fibrosis with } \\
\text { volume loss. M. kansasii: cavitation with a } \\
\text { preponderance of upper lobe; parenchymal } \\
\text { infiltration. }\end{array}$ \\
\hline Shitrit et al. $(2008)^{49}$ & Israel & $\begin{array}{l}\text { M. simiae }(n=102) \\
\text { M. kansasii }(n=62)\end{array}$ & CT & $\begin{array}{l}\text { M. kansasii: cavitation and a predilection for } \\
\text { upper lobe; infiltration. } \\
\text { M. simiae: infiltration, cavitation; pleural effusion; } \\
\text { lymphadenopathy }\end{array}$ \\
\hline Park et al. $(2010)^{37}$ & Seoul, Korea & 41 & CT & $\begin{array}{l}\text { Nodules; consolidation; cavitation; } \\
\text { bronchiectasis; pleural effusion; } \\
\text { lymphadenopathy }\end{array}$ \\
\hline Matveychuk et al. $\left(2012^{158}\right.$ & Tel Aviv, Israel & 98 & CT & $\begin{array}{l}\text { M. kansasii: more cavitations, unilateral disease, } \\
\text { right upper lobe disease more common; } \\
\text { pleural effusion; lymphadenopathy; Other } \\
\text { NTM: infiltration and cavitation; lower and } \\
\text { middle lobe predominance; pleural effusion; } \\
\text { lymphadenopathy }\end{array}$ \\
\hline Baghaei et al. $(2012)^{38}$ & Tehran, Iran & 26 & CT & $\begin{array}{l}\text { M. simiae: Nodular lesion; cavitation; } \\
\text { bronchiectasis }\end{array}$ \\
\hline Kobashi et al. $(2013)^{52}$ & Kawasaki, Japan & 220 & CT & $\begin{array}{l}\text { M. avium, } M . \text { intracellulare and } M . \text { kansasii: } \\
\text { bronchiectatis; cavitation; pneumothorax; }\end{array}$ \\
\hline Gommans et al. $(2015)^{50}$ & $\begin{array}{l}\text { Maastricht/The } \\
\text { Netherlands }\end{array}$ & 124 & $\mathrm{CT}$ & $\begin{array}{l}\text { MAC: cavitation; bronchiectasis; consolidation; } \\
\text { M. kansasii: cavitations, nodules, bronchiectasis } \\
\text { consolidation; M. malmoense: cavitations, } \\
\text { consolidation; MCR: cavitation, nodules; Non- } \\
\text { MNT findings: atelectasis; pleural effusion; } \\
\text { tumors }\end{array}$ \\
\hline Yoon et al. $(2016)^{59}$ & Seoul, Korea & 5 & CT & $\begin{array}{l}\text { MAC: apical fibrocavitary disease; } \\
\text { nodular infiltrates frequently involving the } \\
\text { right middle lobe and the lingula; pleural } \\
\text { hydropneumothorax; consolidation; tree-in-bud } \\
\text { pattern; bronchiectasis; pleural effusion; pleural } \\
\text { thickening }\end{array}$ \\
\hline Hwang et al. $(2017)^{51}$ & Seoul, Korea & 488 & $\mathrm{CT}$ & $\begin{array}{l}\text { bronchiectasis and small centrilobular nodules } \\
\text { predominantly in the right middle lobe or lingula; } \\
\text { apical fibrocavitary lesions }\end{array}$ \\
\hline Ueyama et al. $(2016)^{41}$ & Tokyo, Japan & 69 & CT & $\begin{array}{l}\text { Nodule; bronchiectasis; consolidation; subpleural } \\
\text { thickening; interlobular septal thickening; } \\
\text { cavitation; pleural effusion }\end{array}$ \\
\hline Kwak et al. $(2016)^{48}$ & Seoul, Korea & 66 & CT & $\begin{array}{l}\text { Atelectasis; ground-glass opacity; } \\
\text { bronchiectasis; cavitation; nodular and } \\
\text { micronodular lesions; tree-in-bud pattern; } \\
\text { consolidation; pleural effusion }\end{array}$ \\
\hline Monteiro et al. $(2018)^{43}$ & Pará, Brazil & 43 & CT & Cavitation; bronchiectasis; fibrocavitary lesions \\
\hline Cowman et al. $(2018)^{47}$ & $\begin{array}{l}\text { London, United } \\
\text { Kingdom }\end{array}$ & 85 & CT & $\begin{array}{l}\text { M. abscessus, MAC, M. kansasii, M xenopi and } \\
\text { other species of NTMs: cavitation; nodules; } \\
\text { bronchiectasis; tree-in-bud changes }\end{array}$ \\
\hline Hirama et al $(2019)^{42}$ & Toronto, Canada & 94 & CT and X-ray & $\begin{array}{l}\text { cavitation; bronchiectasis; centrilobular nodules/ } \\
\text { tree-in-bud; random nodules; consolidation/ } \\
\text { ground glass opacity; pleural effusion; pleural } \\
\text { thickening; mediastinal lymphadenopathy }\end{array}$ \\
\hline Cowman $(2018)^{40}$ & $\begin{array}{c}\text { London, } \\
\text { United Kingdom }\end{array}$ & $(-)$ & CT & $\begin{array}{l}\text { tree-in-bud; consolidation; atelectasis; fibrotic } \\
\text { changes; volume loss and pleural thickening }\end{array}$ \\
\hline Bakuła et al. $(2018)^{60}$ & Warsaw, Poland & 105 & CT and X-ray & $\begin{array}{l}\text { Infiltration; interstitial pattern/fibrosis; cavitation; } \\
\text { nodules; bronchiectasis; massive fibrotic lesions; } \\
\text { pleural effusion; mediastinal lymphadenopathy }\end{array}$ \\
\hline De Marca et al. $(2019)^{53}$ & $\begin{array}{l}\text { Rio de Janeiro, } \\
\text { Brazil }\end{array}$ & 48 & CT & $\begin{array}{l}\text { M. kansasii, MAC, M. fortuitum, M. gordonae, } \\
\text { M. abscessus: architectural distortion; reticular } \\
\text { opacities; bronchiectasis; cavitation; centrilobular } \\
\text { nodules; atelectasis; small and large } \\
\text { consolidations. }\end{array}$ \\
\hline
\end{tabular}

1 - (-) is a review article with no patients; 2 - CT: computed tomography; 3 - MAC: Mycobacterium avium complex. 


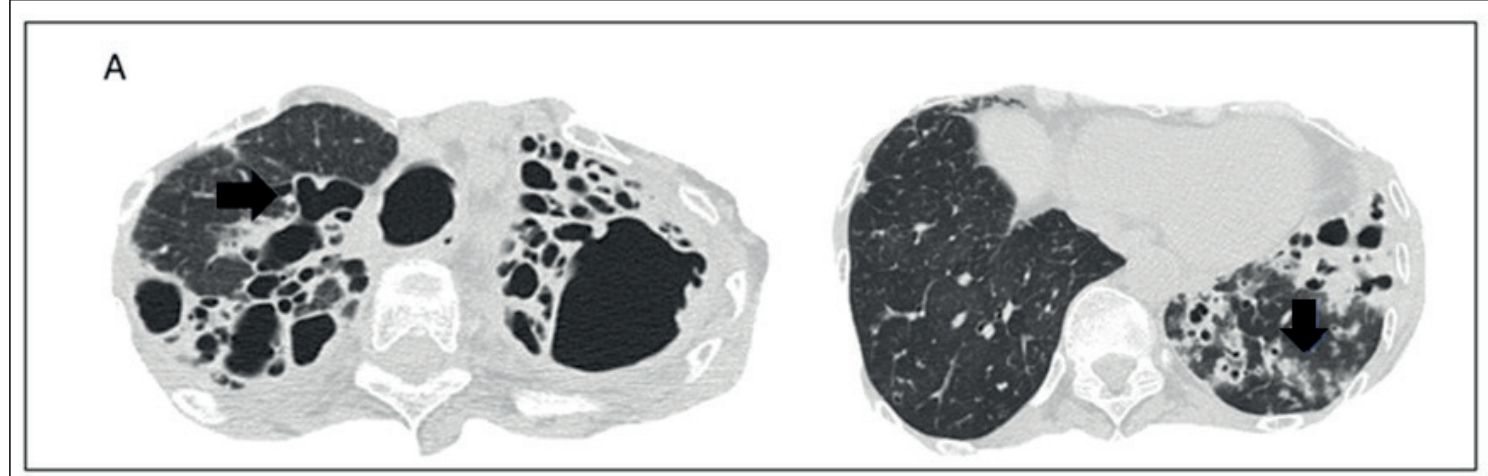

B
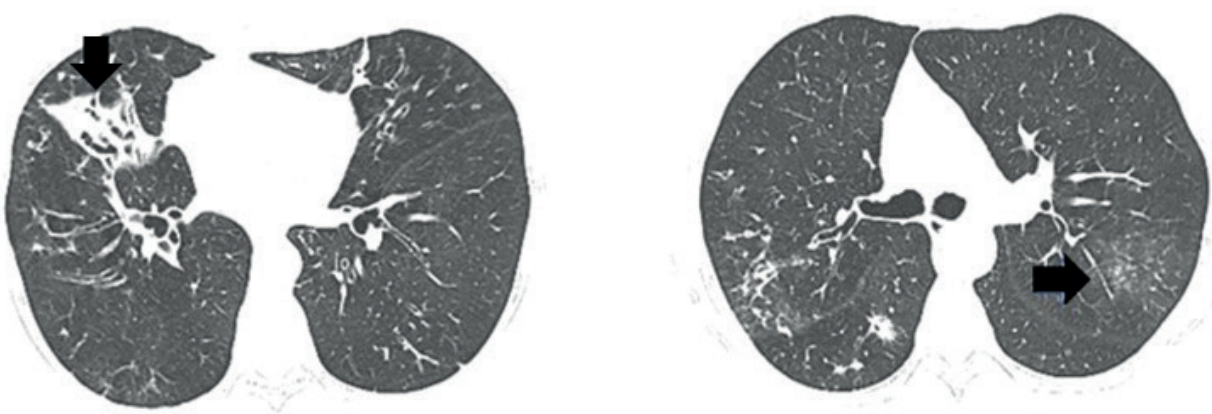

FIGURE 2: (A) CT scan of an immunocompromised patient with $M$. asiaticum; extensive varicose bronchiectasis is observed in a severe form of the disease associated with bronchial parietal thickening (black arrow). Centrilobular opacities with attenuation in "ground-glass" are also visible (black arrow). (B) CT scan of patients with M avium-intracelulare; consolidation of the middle lobe. The associated bronchiectasis predominance of the middle lobe and lingual are noted (black arrow). Centrilobular opacities with attenuation in "ground-glass" is also evident (black arrow).
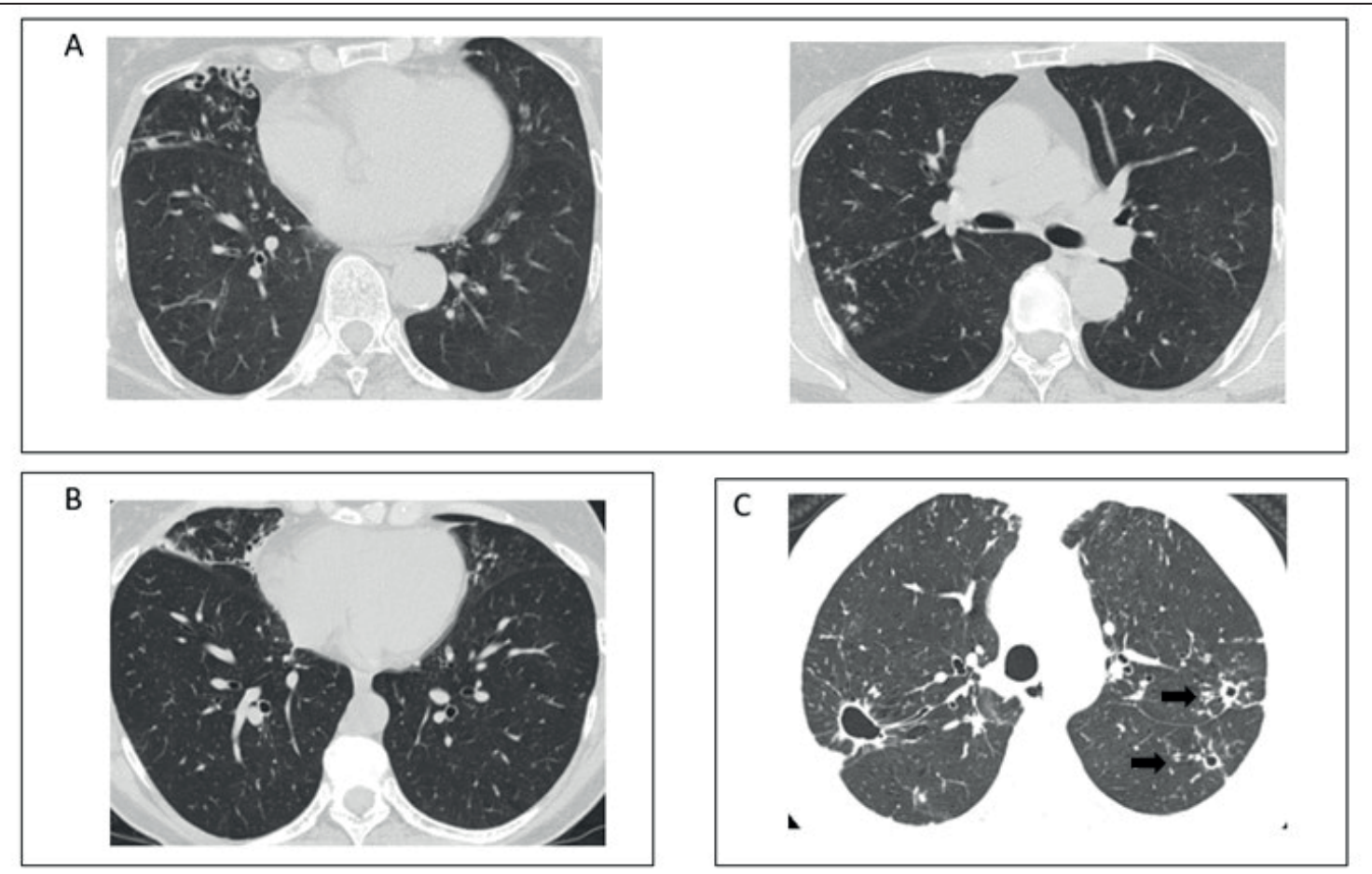

FIGURE 3: (A) CT scan of a patient with M. fortuitum; bronchiectasis in the middle lobe is associated with micronodules in the right upper lobe. (B) CT scan of a patient with M. intracelulare; bronchiectasis and micronodules is visible in the middle lobe and lingula. (C) Cavitation with thick walls in the upper lobes and centrilobular micronodules and some with "budding tree" pattern in the left upper lobe (black arrows). 
dyspnea, hemoptysis, chest pain, fever, asthenia, weight loss, shortness of breath, and night sweats ${ }^{10,23,29}$. It is common for the patient with this manifestation to also develop underlying diseases such as TB, chronic obstructive pulmonary disease (COPD), or pneumoconiosis ${ }^{10,16,29,30}$. Fibrocavitary disease is more common in males over 50 years of age and among Caucasian population and smokers ${ }^{28}$. Advanced cases might result in respiratory failure within 1 to 2 years after the onset of the disease. This predisposing condition is responsible for the highest mortality rate caused by NTM-LD ${ }^{29-31}$.

Nodular bronchiectasis has a much slower progression rate and typically has no underlying $\mathrm{LD}^{32}$. Furthermore, hypersensitivity pneumonitis is considered an inflammatory reaction caused by the inhalation of large quantities of aerosols containing NTMs ${ }^{29,33}$. The signs and symptoms of nodular bronchietasia and hypersensitivity pneumonitis are similar to fibrocavitary disease and in all cases, the diagnosis is made from evidences found via chest radiography or $\mathrm{CT}^{28,29}$.

\section{RADIOLOGICAL DIAGNOSIS}

Current diagnostic criteria of NTM-LD were established in 2007 by the American Thoracic Society (ATS) and the Infectious Diseases Society of America (IDSA). Since then, diagnosis is based on clinical evidence, microbiological identification, and radiological findings $\mathrm{s}^{4,34}$. Various studies describing the tomographic appearance of NTM-LD have been performed over time and these are listed in Table $\mathbf{1 .}$

This review noted that $77.8 \%$ of the articles on NTM-LD published between 1999 and 2019 described bronchiectasis among their CT findings (Table 2). Bronchiectasis is characterized by permanent and abnormal dilation of the bronchi triggered after persistent bacterial airway infection ${ }^{35}$. Figure 2A and Figure 2B show representative images of CT scans showing bronchiectasis in an anonymous patient who was diagnosed with NTM-LD according to the ATS and IDSA criteria.

A study by Fujita et al. (1999) suggests that discrete nodule bronchiectasis is an important radiological finding of MAC infection and colonization ${ }^{36}$. Another study conducted with the Korean population revealed that bronchiectasis was associated with lung colonization by M. kansasii in LD patients ${ }^{37}$. Baghaei et al. (2012) also associated bronchiectasis with LD caused by $M$. simiae among the Iranian population ${ }^{38}$.

Another study by Bonnet et al. (2017) showed that approximately two-thirds of patients with NTM-LD also had fibrocavitary disease with bronchiectasis $(60 \%)$ and cavitation $(40 \%)^{39}$. Bronchiectasis is also among the most predominantly identified radiological observations in CT scans of patients with NTM infection as described in a study conducted by Cowman and Loebinger $(2018)^{40}$.

Ueyama et al. (2016) also reported that bronchiectasis was observed via CT images among $96 \%$ of adult patients with NTMLD evaluated in their study ${ }^{41}$. In the study by Hirama, Brode and Marras (2018), it was identified that $42.6 \%$ of the patients with LD by $M$. xenopi also presented nodular bronchiectasis based on CT scans ${ }^{42}$. Interestingly, in this retrospective study, patients with nodular bronchiectasis were predominantly female. These patients had characteristics which were suggestive of milder disease and were treated less frequently. In addition, these patients received

TABLE 2: Frequency of studies that report radiological findings among NMT infections as described in the articles included in this review.

\begin{tabular}{|c|c|c|c|c|c|}
\hline \multirow{2}{*}{ Radiological finding } & \multicolumn{2}{|c|}{ Number of studies that identified ${ }^{*}$} & \multicolumn{2}{|c|}{ Number of studies that did not identify } & \multirow{2}{*}{$\frac{\text { Total studies }}{n}$} \\
\hline & $\mathbf{n}$ & $\%$ & $\mathbf{n}$ & $\%$ & \\
\hline Pulmonary cavitation & 16 & 88.9 & 2 & 11.1 & 18 \\
\hline Bronchiectasis & 14 & 77.8 & 4 & 22.2 & 18 \\
\hline Pulmonary nodules & 10 & 55.6 & 8 & 44.4 & 18 \\
\hline Consolidation & 9 & 50.0 & 9 & 50.0 & 18 \\
\hline Pleural effusion & 9 & 50.0 & 9 & 50.0 & 18 \\
\hline $\begin{array}{c}\text { Fibrotic alteration/loss } \\
\text { of volume/architectural } \\
\text { distortion }\end{array}$ & 7 & 38.9 & 11 & 61.1 & 18 \\
\hline Ground-Glass Opacities & 6 & 33.3 & 12 & 66.7 & 18 \\
\hline Lymphadenopathy & 5 & 27.8 & 13 & 72.2 & 18 \\
\hline Others Pleural Diseases & 4 & 22.2 & 14 & 77.8 & 18 \\
\hline Atelectasis & 4 & 22.2 & 14 & 77.8 & 18 \\
\hline "Budding tree" pattern & 4 & 22.2 & 14 & 77.8 & 18 \\
\hline $\begin{array}{c}\text { Hydropneumothorax / } \\
\text { pneumothorax }\end{array}$ & 2 & 11.1 & 16 & 88.9 & 18 \\
\hline Bronchiolitis & 1 & 5.6 & 17 & 94.4 & 18 \\
\hline
\end{tabular}

\footnotetext{
*The data are reported considering the absolute $(n)$ and relative (\%) frequencies of the radiological findings described in the articles included in this study.
} 
fewer anti-mycobacterial drugs during treatment. Taken together, these results were not sufficient to determine a specific radiological pattern for LD by M. xenopi $i^{42}$.

In Brazil, a study on clinical aspects of patients with LD by MABSC identified the presence of nodular bronchiectasis in individuals diagnosed with NTM infection but were not undergoing any treatment. However, these results are not sufficient to determine a radiological standard for NTM-LD findings ${ }^{43}$.

It should be noted that some of the studies cited here were performed in patients with cystic fibrosis who had a predisposition to changes such as bronchiectasis ${ }^{44}$. Hence, it is not possible to state whether the onset of bronchiectasis favors lung colonization by NTMs or vice versa ${ }^{45,46}$.

This characterization of bronchial alterations as an important radiological finding of NTM-LD is relevant for the diagnosis and also for the patient recovery. A study by Cowman et al. (2018) suggested that bronchiectasis interfered with the duration of the disease and was associated with severe lung disease prognosis ${ }^{47}$.

Another obstacle for the radiological diagnosis of NTM-LD was highlighted by Bonnet et al. (2017) where the authors showed that CT scans from TB patients also feature post-inflammatory bronchiectasis $^{39}$. According to Kwak et al. (2016), NTM-LD and pulmonary $\mathrm{TB}$ bronchiectasis are difficult to distinguish and, therefore, it is necessary to observe other radiological characteristics ${ }^{48}$, such as, cavities and distribution of pulmonary changes in CT images. Compared with pulmonary TB, NTMLD tends to form cavities less frequently ${ }^{56}$ and involves more of the middle and/or lower lung regions and bilateral lungs more frequently ${ }^{57}$.

This review found that $55.6 \%$ and $88.9 \%$ of the articles indicate presence of pulmonary nodules and presence of cavitation on CT images of patients with NTM-LD, respectively (Table 2). Figure $3 C$ represents CT images of patients with NTM-LD who presented cavitation and pulmonary nodules based on radiological findings.

Pulmonary nodules were also identified in $98 \%$ of adult patients with NTM-LD evaluated in the study by Ueyama et al. (2016). Interestingly, in that study, other findings were also reported, including cavitation ( in $77 \%$ of patients) ${ }^{41}$.

Studies by Shitrit et al. (2008) and Matveychuck et al. (2012) conducted among Israeli population revealed numerous upper lobe cavitations in patients with $M$. kansasii infection ${ }^{49,58}$. In a subsequent study, the prevalence of thin-walled cavities in upper lobes of patients with infections caused by NTMs was also observed. In these cases, some pleural abnormalities around the cavities were observed ${ }^{16}$.

In the study by Shitrit et al. (2008), pleural abnormalities and lymphadenopathy were also identified. However, in this study, these abnormalities were only associated with the presence of pulmonary infiltrates located in the middle and upper lobes among patients with infections caused by $M$. simia ${ }^{49}$. On the other hand, it has been reported that MTBC is also capable of promoting cavitation formation. Thus, it was concluded that cavitations are nonspecific alterations of NTM-LD and might reflect infections caused by several pathogens commonly found in diseases that compromise airway functions ${ }^{4,24}$.
This review identified other radiological findings such as pleural effusion and mediastinal lymphadenopathy, which were observed in a study by Bakula et al. (2018). Other findings of this study were consolidation (50\%), ground-glass opacities (33.3\%), other pleural diseases (22.2\%), pleural lymphadenopathy (27.8\%), atelectasis (22.2\%), "budding tree" pattern (22.2\%), fibrotic alteration / volume loss / pulmonary architecture distortion (38.9\%), hydropneumotorax / pneumothorax (11.1\%), and bronchiolitis (5.6\%). All the findings are summarized in Table 2.

Gommans et al. (2014) pointed out that the variability observed among radiological findings of infections caused by NTMs is common and is dependent on the species causing infection. Furthermore, it is suggested that the presence of consolidation on CT images of patients diagnosed with NTM infection is an important predictor of mortality ${ }^{50}$. On the other hand, Hwang et al. (2017) suggested that the presence of fibrocavitary alterations and advanced age are negative prognostic factors for survival of patients with LD by MAC ${ }^{51}$.

These fibrocavitary changes were associated with $39.4 \%$ of the cases of LD due to M. xenopi based on a study by Hirama et al. $(2019)^{42}$. Cowman and Loebinger (2018) had previously identified these fibrocavitary changes in CT scans of patients with NTM infections ${ }^{40}$. In the same study, consolidation was suggested as a common radiological finding ${ }^{40}$.

Additionally, studies by Kobashi et al. (2013) and Ueyama et al. (2016) revealed that pneumothorax has been recognized in the lungs of certain patients diagnosed with NTM infections ${ }^{41,52}$. Yoon et al. (2016) also suggested that the presence of pneumothorax in CT scans is indicative of the spread of MAC infection but the meaning of this association is not clear ${ }^{59}$.

The loss of lung mass volume is also a characteristic that is frequently identified among the radiological findings of patients with lung diseases. De Marca et al. (2019) suggested that there is a relationship between mass and lung functions, however, this relationship is not yet fully elucidated ${ }^{53}$.

Although all the findings described above are not specific towards a definitive NTM-LD diagnosis, it is described in the literature that the disease form with nodular infiltrates and bronchiectasis frequently affects the middle lobe and lingula regions $^{37,41}$. Representative images of these alterations are shown in Figures 3A and Figure 3B.

\section{THERAPY}

The objective of treatment against NTM-LD is to improve the patient's quality of life by monitoring signs and symptoms. Treatment against NTM infection is long and lasts for 18 to 24 months. The patient is considered cured when he/she is negative for sputum culture for 12 consecutive months ${ }^{54}$. Treatment is a complex decision that involves measuring the benefits and the risk of drug toxicity ${ }^{11}$.

The choice of drug, in general, is directed towards the elimination of the disease-causing NTM species. Microbial susceptibility testing is recommended prior to initiation of treatment. Traditionally, treatment of NTM-LD by MAC consists of the combined use 
of macrolides (claritormycin or azithromycin), rifampicin and ethambutol ${ }^{11}$. Certain cases of resistance against macrolides and amikacin have already been reported and this resistant or refractory form can be treated alternatively with moxifloxacin, aminoglycosides and clofazimine $e^{11,55}$.

M. kansassi is sensitive to anti-TB drugs and is treated with rifampicin, isoniazid, rifabutin, ethambutol, fluoroquinolones, and amikacin ${ }^{11}$. The pulmonary infection caused by MABSC is progressively slow and its treatment is based on the combined use of intravenous amikacin with cefoxitin or imipenem and an oral macrolide ${ }^{21,29,54}$. Information on the effectiveness of this treatment is limited and there is evidence that MABSC is resistant to various antibiotics $^{21,54}$.

Despite these treatment options, it should be noted that the patient is subjected to side effects, reactions and drug interactions. In the case of macrolides, gastrointestinal discomfort is commonly observed. Use of rifampicin, imipenem and tigecycline might cause hepatotoxicity and rifampicin might alter the metabolism of other medicines such as contraceptives. The use of aminoglycosides, in turn, might cause renal toxicity and hearing impairment ${ }^{11}$. The use of linezoline and ethambutol might cause peripheral neuropathy and ethambutol could also lead to decreased visual acuity ${ }^{11}$.

In general, it is suggested that treatment should begin within hospital units ${ }^{11}$. In cases where response to chemotherapy is not efficient, surgical resection should be considered and must be conducted by a multidisciplinary technical team ${ }^{11,21}$.

\section{CONCLUSIONS}

The increased incidence associated with the complexity of diagnosis makes NTM-LD a public health concern. Correct and rapid diagnosis is critical for the proper and effective choice of treatment. Currently, diagnostic criteria include clinical evidence, microbiological identification, and radiological findings. NTM-LD symptoms are similar to other pulmonary infections. Microbiological identification is not always possible. Based on the radiological alterations observed in NTM-LD, bronchiectasis, cavitations and pulmonary nodules are predominantly found. Although these alterations overlap with other lung diseases, when they are predominantly found in the middle lobe and lingula, mycobacteriosis should be suspected.

\section{ACKNOWLEDGMENTS AND FINANCIAL SUPPORT}

This work was supported by the Brazilian National Council for Scientific and Technological Development (CNPq) and by Coordenação de Aperfeiçoamento de Pessoal de Nível Superior (CAPES).

\section{AUTHOR CONTRIBUTIONS}

The authors LRBA, PLP, PPTST, AK, APJK and MFR equally contributed to the analysis of the literature, selection of images, and in writing this article.

\section{CONFLICT OF INTEREST}

The authors declare no conflict of interest.

\section{REFERENCES}

1. Trabulsi LR, Alterthum F. Mycobacterium. Ducati RG, Leão SC, Basso LA, Santos, DS, editors. Microbiologia In: 6 th ed. São Paulo: ed. Atheneu; 2015. p. 424-45.

2. Kweon O, Kim S-J, Blom J, Kim S-K, Kim B-S, Baek D-H, et al. Comparative functional pan-genome analyses to build connections between genomic dynamics and phenotypic evolution in polycyclic aromatic hydrocarbon metabolism in the genus Mycobacterium. Biomed Cent. 2015;15(21):1-23.

3. Murray PR, Rosenthal KS, Pfaller MA. Mycobacterium. Microbiologia Médica In: 3 rd ed. Rio de Janeiro: ed Elsevier; 2014. p. 513-30.

4. Baldwin SL, Larsen SE, Ordway D, Cassell G, Coler RN. The complexities and challenges of preventing and treating nontuberculous mycobacterial diseases. Plos Negleted Trop Dis. 2019;13(2):1-23.

5. Tan Y, Su B, Shu W, Cai X, Kuang S, Kuang H, et al. Epidemiology of pulmonary disease due to nontuberculous mycobacteria in southern. BMC Pulm Med. 2018;18(168):1-7.

6. Jagielski T, Minias A, van Ingen J, Rastoji N, Brzostek A, Zaczek A, et al. Methodological and clinical aspects of the molecular epidemiology of Mycobacterium tuberculosis and other mycobacteria. Clin Microbiol Rev. 2016;29(2):239-90.

7. Panagiotou M, Papaioannou AI, Kostikas K, Paraskeua M, Velentza E, Kanellopoulou M, et al. The epidemiology of pulmonary nontuberculous mycobacteria: data from a general Hospital in Athens, Greece, 2007 2013. Pulm Med. 2014;2014(1):1-9.

8. Velayati AA, Farnia P, Mozafari M, Malekshahian D, Seif S, Rahideh S, et al. Molecular epidemiology of nontuberculous mycobacteria isolates from clinical and environmental sources of a metropolitan city. PLoS One. 2014;9(12):1-12.

9. Billinger ME, Olivier KN, Viboud C, Montes de Oca R, Steiner C, Holland SM, et al. Nontuberculous mycobacteria - associated lung disease in hospitalized persons. Emerg Infect Dis. 2009;15(10):19982005.

10. Mirsaeidi M,Farnia P, Sadikot R, Hsued P-R, Aliberti S. Nontuberculous mycobacteria: epidemiologic, mycobacteriologic, and clinical aspects. Biomed Res Int. 2015;2015:523697.

11. Chalmers JD, Aksamit T, Carvalho ACC, Rendon A, Franco I. Nontuberculous mycobacterial pulmonary infections. J Pulmonol. 2018;24(2):120-31.

12. Haworth CS, Banks J, Capstick T, Fisher AJ, Gorsuch T, Laurenson IF, et al. British thoracic society guidelines for the management of nontuberculous mycobacterial pulmonary disease (NTM-PD). BTS Guidel. 2017;72(2):1-64.

13. Dall Bello AG., Severo CB., Oliveira FDM, Hallal Junior RJ, Hochhergger B, Severo LC. Histoplasmosis presenting with multiple pulmonary nodules. A case mimicking radiological features of pulmonary metastasis. Rev Inst Med trop S Paulo. 2013;55(3):209-11.

14. Shikanai-Yasuda MA, Mendes RP, Colombo AL, Queiroz-Telles FD, Kono ASG, Paniago AM et al.. Brazilian guidelines for the clinical management of paracoccidioidomycosis. Rev Soc Bras Med Trop. 2017;50(5):715-40.

15. Hu C, Huang L, Cai M, Wang W, Shi X, Chen W. Characterization of non-tuberculous mycobacterial pulmonary disease in Nanjing district of China. BMC Infect Dis. 2019;19(764):1-8.

16. Johnson MM, Odell JA. Nontuberculous mycobacterial pulmonary infections. J Thorac Dis. 2014;6(3):210-20.

17. Prevots DR, Shaw PA, Strickland D, Jackosn LA, Raebel MA, Blosky $\mathrm{MA}$, et al. Nontuberculous mycobacterial lung disease prevalence at 
four integrated health care delivery systems. Am J Respir Crit Care Med. 2010;182(7):970-6.

18. Habib S, Rajdev K, Pervaiz S, Siddiqui AH, Azam M, Chalhoub M. Pulmonary cavitary disease secondary to Mycobacterium xenopi complicated by respiratory failure case presentation. Cureus. 2018;10(10):1-6.

19. Hurst-Hess K, Rudra P, Ghosh P. Mycobacterium abscessus whiB7 regulates a species-specific repertoire of genes to confer extreme antibiotic resistance. Antimicrob Ag. 2017;61(11):1-11.

20. Steindor M, Nkmouano V, Stefanski A, Stuehler K, Ioerger TR, Bogumil $\mathrm{D}$, et al. A proteomics approach for the identification of species-specific immunogenic proteins in the Mycobacterium abscessus complex. Microbes Infect. 2018;21(3-4):154-62.

21. Jeon K, Kwon OJ, Lee NY, Kim B-J, Kook Y-H, Lee S-H, et al. Antibiotic treatment of Mycobacterium abscessus lung disease a retrospective analysis of 65 patients. Am J Respir Crit Care Med. 2009;180(9):896-902.

22. Lin C, Russel C, Soll B, Chow D, Bamrah S, Brostrom R, et al. Increasing prevalence of nontuberculous mycobacteria in respiratory specimens from US-Affiliated Pacific. Emerg Infect Dis. 2018;24(3):485-91.

23. Carneiro MS, Nunes LS, De David SMM, Dias CF, Bartg AL, Unes G. Nontuberculous mycobacterial lung disease in a high tuberculosis incidence setting in. J Bras Pneumol. 2018;44(2):106-11.

24. Floto RA, Olivier KN, Saiman L, Daley CL, Herrmann J-L, Nick J-A, et al. US Cystic Fibrosis Foundation and European Cystic Fibrosis Society consensus recommendations for the management of non-tuberculous mycobacteria in individuals with cystic fi brosis. Thorax. 2016;71(1):1-22 .

25. Werf MJVD, Ködmön1 C, Katalinić-Janković V, Kummil T, Soini H, Richter E, et al. Inventory study of non-tuberculous mycobacteria in the European Union. BMC Infect Dis. 2014;14(62):1-9.

26. Albrecht C, Ringshousen F, Ott S, Wagner D, Rademacher J, Schneider $\mathrm{M}$, et al. Should all adult cystic fibrosis patients with repeated nontuberculous mycobacteria cultures receive specific treatment? A 10year case - control study. Eur Respir J. 2016;47(1):1575-7.

27. Mehta M, Marras TK. Impaired health-related quality of life in pulmonary nontuberculous mycobacterial disease. Respir Med. 2011;105(11):1718-25.

28. Larsson LO, Polverino E, Hoefsloot W, Codecasa LR, Diel R, Jenkins $\mathrm{SG}$, et al. Pulmonary disease by non-tuberculous mycobacteria - clinical management, unmet needs and future perspectives. Expert Rev Respir Med. 2017;11(12):977-89.

29. Griffith DE, Aksamit T, Brown-Elliot BA, Catanzaro A, Daley C, Gordin F, et al. American Thoracic Society Documents an Official ATS / IDSA Statement: diagnosis, treatment, and prevention of nontuberculous mycobacterial diseases. Am Thorac Soc Doc. 2007;175(4):367-416.

30. Stout JE. Evaluation and management of patients with pulmonary nontuberculous mycobacterial infections. Expert Rev Anti Infect Ther. 2006;4(6):981-93.

31. Hayashi M, Takayanagi N, Kanauchi T, Miyahara Y, Yanagisawa T, Sugita Y. Prognostic factors of 634 HIV-negative patients with Mycobacterium avium complex lung disease. Am J Respir Crit Care Med. 2012;185(5):575-83.

32. Weiss CH, Glassroth J. Pulmonary disease caused by nontuberculous mycobacteria. Expert Rev Respir Med. 2012;6(6):597-613.

33. Falkinham JO $\underline{3 r d}$. Nontuberculous mycobacteria in the environment. Clin Chest Med. 2002;23(3):529-51.

34. Jarand J, Levin A, Zhang L, Huitt G, Mitchell JD, Daley CL. Clinical and microbiologic outcomes in patients receiving treatment for Mycobacterium abscessus pulmonary disease. Clinical Infectious

\section{Disease. 2011;52(1):565-71.}

35. King PT. The Role of the immune response in the pathogenesis of bronchiectasis. Biomed Res Int. 2018;2018:6802637.

36. Fujita J, Ohtsuki Y, Suemitsu I, Shigeto E, Yamadori I, Obayashi Y, et al. Pathological and radiological changes in resected lung specimens in Mycobacterium avium intracellulare complex disease. Eur Respir J. 1999;13(3):535-40.

37. Park HK, Koh W-J, Shim TS, Kwon J. Clinical characteristics and treatment outcomes of Mycobacterium kansasii lung disease in Korea. Yonsei Med J. 2010; 51(4):552-6.

38. Baghaei P, Tabarsi P, Farnia P, Marjani M, Sheikholeslami F-M, Chitsaz M, et al. Pulmonary disease caused by Mycobacterium simiae in Iran 's national referral center for tuberculosis. J Infect Dev Ctries. 2012;6(1):23-8.

39. Bonnet M, San KC, Pho Y, Sok C, Dousset J-P, Brant W, et al. Nontuberculous mycobacteria infections at a provincial Reference Hospital, Cambodia. Emerg Infect Dis. 2017;23(7):1139-47.

40. Cowman SA, Loebinger MR. Diagnosis of nontuberculous mycobacteria lung disease. Semin Respir Crit Care Med. 2018;39(03):343-50.

41. Ueyama M, Asakura T, Morimoto K, Namkoong H, Matsuda S, Osawa $\mathrm{T}$, et al. Pneumothorax associated with nontuberculous mycobacteria. Medicine. 2016;95(29):1-9.

42. Hirama T, Brode SK, Marras TK. Radiologic types of Mycobacterium xenopi pulmonary disease: different patients with similar short-term outcomes. Eur J Clin Microbiol Infect Dis. 2019;38(2):373-81.

43. Monteiro JTC, Lima KVB, Barreto AR, Furlaneto IP, Gonçalves GM, da Costa ARF, et al. Clinical aspects in patients with pulmonary infection caused by mycobacteria of the Mycobacterium abscessus complex, in the Brazilian Amazon. J Bras Pneumol. 2018;44(2):93-8.

44. Redondo M, Keyt H, Dhar R, Chalmers JD. Global impact of bronchiectasis and cystic fibrosis. Breathe. 2016;12(3):222-35.

45. Bonaiti G, Pesci A, Marruchella A, Lapadula G, Gori A, Aliberti S. Nontuberculous mycobacteria in noncystic fibrosis bronchiectasis. Biomed Res Int. 2015;2015:197950.

46. Koh W-J, Kwon OJ, Kyung SL. Nontuberculous mycobacterial pulmonary diseases in immunocompetent patients. Korean J Radiol. 2002;3(3):145-57.

47. Cowman SA, Jacob J, Obaidee S, Floto RA, Wilson R, Haworth CS, et al. Latent class analysis to define radiological subgroups in pulmonary nontuberculous mycobacterial disease. BMC Pul. 2018;18(1):1-8.

48. Kwak N, Lee C-H, Lee H-J, Kang YA, Lee JH, Han SK, et al. Nontuberculous mycobacterial lung disease: diagnosis based on computed tomography of the chest. Eur Soc Radiol. 2016;26(12):4449-56.

49. Shitrit D, Peled N, Bishara J, Priess R, Pitlik S, Samra Z, et al. Clinical and radiological features of Mycobacterium kansasii infection and Mycobacterium simiae infection. Respir Med. 2008;102(11):1598-603.

50. Gommans EPAT, Even P, Linssen CFM, van Dessel H, van Haren E, de Vries GJ, et al. Risk factors for mortality in patients with pulmonary infections with non-tuberculous mycobacteria: A retrospective cohort study. Respir Med. 2015; 109(1):137-45.

51. Hwang JA, Kim S, Jo K-W, Shim TS. Natural history of Mycobacterium avium complex lung disease in untreated patients with stable course. Eur Respir. 2017;49(3):1600537.

52. Kobashi Y, Mouri K, Obase Y, Kato S, Oka M. Clinical analysis of patients with pulmonary nontuberculous mycobacterial disease complicated by pneumothorax. Inter Med. 2013;52(22):2511-15. 
53. De Marca PGC, Goldenberg T, Mello FCQ, Carvalho ARS, Guimarães, ARM, Mogami R, et al. Pulmonary densitovolumetry using computed tomography in patients with nontuberculous mycobacteria: correlation with pulmonary function tests. Pulmonary Medicine. 2019;2019(5942783):1-9.

54. Kwak N, Dalcolmo MP, Daly CL, Eather G, Gayoso R, Hasegawa N, et al. Mycobacterium abscessus pulmonary disease: individual patient data meta-analysis. Eur Respir J. 2019;2019(March):1-48.

55. Luo J, Yu X, Jiang G, Fu Y, Huo F, Ma Y, et al. In vitro activity of clofazimine against nontuberculous Mycobacteria Isolated in Beijin, China. Antimicrob Agents Chemother. 2018;62(7):1-9.

56. Kendall BA, Varley CD, Choi D, Cassidy M, Hedberg K, Ware MA, et al. Distinguishing tuberculosis from nontuberculous mycobacteria lung disease, Oregon, USA. Emerg Infect Dis. 2011;17(3):506-9.
57. Kow W-J, Yu C-M, Su GY, Chung MP, Kim H, Kwon OJ, et al. Pulmonary TB and NTM lung disease: comparison of characteristics in patients with AFB smear-positive sputum. The International Journal of Tuberculosis and Lung Disease. 2006;10(9):1001-7.

58. Matveychuck A, Fuks L, Priess R, Hahim I, Shitrit D. Clinical and radiological features of Mycobacterium kansasii and other NTM infections. Respiratory Medicine. 2012;106(1):1472-7.

59. Yoon HJ, Chung MJ, Lee KS, Kim JS, Park HY, Koh W-J. Broncho-Pleural Fistula with Hydropneumothorax at CT: Diagnostic Implications in Mycobacterium avium Complex Lung Disease with Pleural Involvement. Korean J Radiol. 2016;17(2):295-301.

60. Bakula Z, Kościuch J, Safianowska A, Proboszcz M, Bielecki J, van Ingen J, Krenke R, et al. Clinical, Radiological and Molecular Features of Mycobacterium Kansasii Pulmonary Disease. Resp Med. 2018;139:91-100. 